\title{
Finite Element Analysis (FEA) and Thermal Gradient of a Solid Rectangular Fin with Embossing's for Aerospace Applications
}

\author{
Joel Hemanth1, K. B. Yogesh² \\ ${ }^{1}$ Presidency University, Bangalore, India \\ ${ }^{2}$ JSS Academy of Technical Education, Bangalore, India \\ Email: joelhemanth@hotmail.com, joelhemanth@gmail.com
}

How to cite this paper: Hemanth, J. and Yogesh, K.B. (2018) Finite Element Analysis (FEA) and Thermal Gradient of a Solid Rectangular Fin with Embossing's for Aerospace Applications. Advances in Aerospace Science and Technology, 3, 49-60. https://doi.org/10.4236/aast.2018.33004

Received: May 31, 2018

Accepted: July 17, 2108

Published: July 20, 2108

Copyright $\odot 2018$ by authors and Scientific Research Publishing Inc. This work is licensed under the Creative Commons Attribution International License (CC BY 4.0).

http://creativecommons.org/licenses/by/4.0/

\begin{abstract}
Fins are the extended surfaces through which heat transfer takes place by conduction and convection to keep the base surface cool. Fins of various configurations are presently used ranging from automobile engines to cooling of chip in a computer. Fins used presently are solid with different shapes but in the present research such solid fins are compared with solid fins having maximum of 10 numbers of embossing's that further increases the surface area for maximum heat transfer. Importance in this research is given to variation of temperature along the length of the fins which in turn gives rate of heat transfer. Thus this research is under taken to increase the efficiency of fins (by extracting heat from the base surface) which is highly demanded today for air cooled engines, compressors, refrigerators etc. In the present research, SOLID70 element and SURF152 elements are used for FE analysis. Methodology involves 3D rectangular fin modelling and meshing, creation of surf elements for the modeling, applying the boundary conditions and source temperature, applying the material property (aluminum) to obtain the steady state thermal contours. FEA results are finally compared with analytic and experimental values for validity. In the present research, a solid rectangular aluminum fin and the same rectangular fin with 2, 4, 8 and 10 embossing's were compared through finite element analysis for its temperature distribution along the length. FEA analysis of the present research showed that fins having embossing's were more efficient compared to that a simple solid fin. Hence it is concluded from the present research that embossing's at preferred locations further increases the rate of heat transfer. From the present analysis it is concluded that the mathematical and FEA for a solid rectangular fin without embossing's are converging within $\pm 1.2^{\circ} \mathrm{C}$ and rectangular fin with 10 embossing's is converging within $\pm 1.4^{\circ} \mathrm{C}$ and hence the validity.
\end{abstract}




\section{Keywords}

Fin, FEA, Temperature, Embossing and Surface

\section{Introduction}

The basic law that governs the convective heat transfer is Newton's law of cooling given by:

$$
Q=h A\left(T_{s}-T_{f}\right) \text {, Watts }
$$

where: $T_{s}$ : the surface temperature ${ }^{\circ} \mathrm{C}$; $T_{\dot{F}}$ the fluid temperature ${ }^{\circ} \mathrm{C}$; $h$ : the convective heat transfer coefficient $\mathrm{w} / \mathrm{m}^{2}{ }^{\circ} \mathrm{C} ; A$ : surface area, $\mathrm{m}^{2}$.

Note that in the above equation, film coefficient of heat transfer or the convective heat transfer coefficient " $h$ " is very important which mainly depends on the type of the surface, size, shape, its temperature, surface finish etc. Most of the research, mathematical analysis and dimensional analysis are confined in finding " $h$ ". In addition to the above, for fins, the temperature distribution along its length also becomes important.

The expulsion of overabundance warmth from framework parts is fundamental to abstain from harming impacts of overheating. Thusly the improvement of warmth exchange is a vital subject of warm designing [1]. Heat exchange rate might be expanded by expanding the warmth exchange coefficient between a surface and its encompassing, or by expanding the warmth exchange zone of the surface. Much of the time, the zone of warmth exchange is expanded by developing surfaces. These amplified surfaces are called as fins.

Balances are utilized to improve convective warmth move in an extensive variety of designing applications and offer a handy method for accomplishing a substantial aggregate warmth exchange surface range without the utilization of an over the top measure of essential surface zone [2]. Fins are generally connected for warmth administration in electrical apparatuses, for example, PC power supplies or substation transformers. Different applications incorporate motor cooling, condensers in refrigeration and aerating and cooling [3]. Fins as warmth exchange improvement gadgets have been very regular. The diverse materials like mild steel, stainless steel, aluminum, and silver, copper and so on are utilized for making fins. As the stretched out surface innovation keeps on developing, new outline thoughts have been risen including fins made of anisotropic composites, permeable media, hindered and punctured plates. Because of popularity for light weight, smaller and sparing fins, the enhancement of balance size is of awesome significance [4].

Along these lines, fins must be intended to accomplish most extreme warmth expulsion with least material use considering the simplicity of the balance fabricating. The change in warmth exchange coefficient is ascribed to the restarting of the warm limit layer after every interference [5]. Accordingly punctured plates 
and fins speak to a case of surface intrusion. Current study intends to foresee the temperature drop more than a few round apertures of expansion in number. Different parameters like warm flux and warm inclination are analyzed over various number of round holes [6]. In this investigation ANSYS FEA software is utilized for lattice and unraveling.

In the examination of warmth trade, cutting edges are surfaces that stretch out from a thing to manufacture the rate of warmth trade to or from nature by growing convection. The measure of conduction, convection, or radiation of an article chooses the measure of warmth it trades [7]. Extending the temperature incline between the article and the earth, growing the convection heat trade coefficient, or extending the surface zone of the thing constructs the glow trade. Occasionally it is not achievable or down to earth to change the underlying two choices. In this way, adding a cutting edge to a thing assembles the surface zone and can rarely be a calm response for warmth trade issues [8].

Finally, it is well known that major heat transfer from the fin is by convection and performance of a fin is evaluated by its efficiency and effectiveness.

\section{Literature Review}

There are various examination related to warmth trade and weight drop of channels with pin cutting edges, which are limited to stick parities with round or couple of different cross territories. The genuine warmth trade takes by two modes i.e. by conduction took after by convection. Heat trade through the solid to the surface of the solid happens through conduction whereas from the surface to the surroundings happens by convection. Further warmth trade may be by normal convection or by obliged convection.

Bayram Sahin and Alparslan Demir [9] from their research concluded that, the use of the square stick cutting edges may incite warmth trade change. Both lower elbowroom extent and lower between parity scattering extent and likewise cut down Reynolds numbers are proposed for higher warm execution. R. Karthikeyan and R. Rathnasamy [10] concluded from their research that, for a given Reynolds number, the pin-edge show with smaller buries fin separation gives higher execution than those with higher cover equalization partitions. Another researcher found that, most in-line square stick equalization bunches have poorer warmth move than an in-line round pin fin cluster show wonderful warmth trade at high Reynolds number. The perfect between equalization pitches are directed by the greatest Nusselt number at a given pumping power [11]. Connections giving the typical Nusselt number for each outline as a part of the Reynolds number were created few researchers [12]. Amol B., Dhumne, Hemant S. and Farkade [13] focused on the trial examination of on warmth exchange upgrade and the relating weight drop over a level surface equipped with barrel molded cross sectional punctured pin equalizations in a rectangular channel. Their research showed that the usage of the barrel formed punctured pin fins prompts heat trade update than the solid round and empty equalizations. Both 
lower breathing space extent and lower between parity scattering extent and nearly cut down Reynolds numbers are proposed for higher warm execution. In one more investigation the researchers found that, glow trade by short stick edges in staggered plans. According to their results, longer stick equalizations $(\mathrm{H} / \mathrm{d}=4)$ trade more warmth than shorter pin-parities $(\mathrm{H} / \mathrm{d}=1 / 2$ and 2$)$ and the exhibit found the center estimation of warmth trade with eight segments of pin-adjusts to some degree surpasses that with only four lines [14]. Vanfossen G. J. and Brigham B. A. [15] focused their research on the ordinary warmth trade coefficient on the pin surface is around $35 \%$ greater than that on the end dividers.

Metzger et al., [16] investigated the effects of pin-edge shape and show presentation on the glow trade and the weight incident in pin-equalization bunches. They demonstrated by their results that the use of round and empty pin-parities with a group introduction amongst astonished and in-line can now and again propel the glow trade, while fundamentally decreasing weight. Others have also reported from their investigation that, another way to deal with upgrade heat swapping scale is touse spaces which allow the stream to encounter the pieces [17]. Yatendra Singh, Tomar, Sahu M. M. [18] mulled over that the warm resistance and weight drop are considered as the distinctive warm execution properties. Their studies have exhibited that the convection heat conversion standard from equalization bunches depends on upon all geometric parameter, parity material and base-to-encompassing temperature contrast. The elliptic pin equalization exhibits the most insignificant weight drops. For the same surface zone at a settled pumping power, the elliptic pin edge has the smallest warm resistance for the stunned course of action [19].

\section{Relevance of the Research}

Fins are the extended surfaces through which heat transfer takes place by conduction and convection. In the present investigation the surface area is further increased by providing embossing's at preferred locations in the solid fin. This in turn increases effectiveness and efficiency of the fin. So far no attempt has been made to provide embossing's in the solid aluminum fin to increase the surface area and hence the present research was under taken to fill the void.

\section{Experimental, Analytical and FE Analysis Procedure}

Figure 1 shows the experimental set up showing temperature recorder, thermocouple etc. along with the heat source at the center, attached with fins having embossing's (MAXM. 10). The power supplied was 40 watts to heat the base of the fin.

In the present research, SOLID70 element and SURF152 elements are used for FE analysis. Methodology involves 3D rectangular fin modelling and meshing, creation of surf elements for the modeling, applying the boundary conditions and source temperature, applying the material property (aluminum) to obtain 


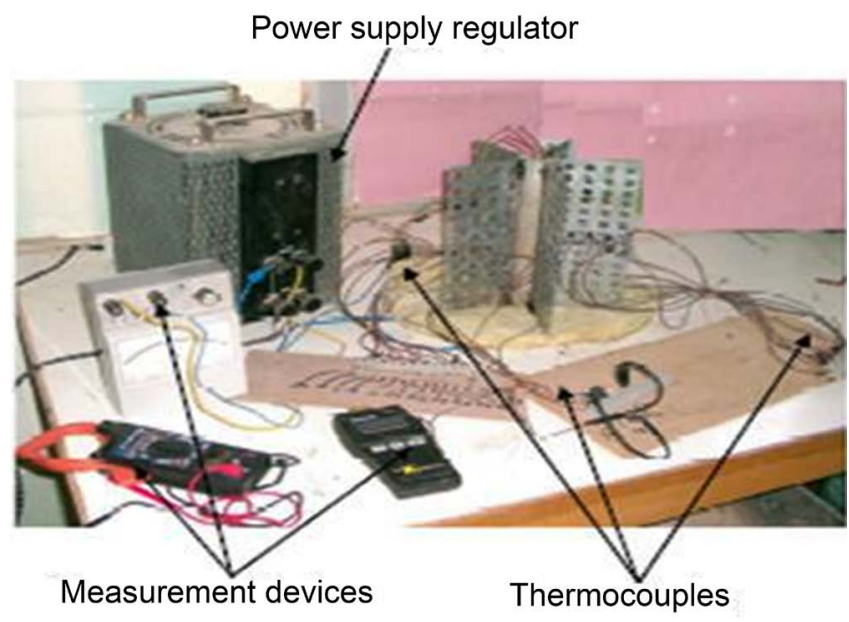

Figure 1. Experimental setup.

the steady state thermal contours. Finally the temperature distribution results of solid fin are compared with that of solid fin with 10 embossing's at preferred locations along the length of the fin.

\subsection{Mathematical Analysis Fora Solid Fin Temperature Gradient}

Figure 2 shows a rectangular aluminum fin indicating the details regarding area, perimeter, temperature etc.

The most popular energy balance equation used to find the heat transfer through fins mathematically (for steady state condition) is given by:

$$
Q=\sqrt{h p K A}\left(C_{2}-C_{1}\right)
$$

where $Q$ : rate of hear transfer, watts, $h$ : convective heat transfer coefficient $\mathrm{w} / \mathrm{m}^{2}{ }^{\circ} \mathrm{C}$; $P$ : the perimeter of the fin, $\mathrm{m}, K$ : thermal conductivity, w/m ${ }^{\circ} \mathrm{C} ; A:$ area, $\mathrm{m}^{2}$ and $C_{1} ; C_{2}$ are constants obtained by applying the limits.

Above equation is modified to find temperature distribution based on the tip condition.

Equation below is used to find analytically the fin temperature over a distance with given boundary conditions [20].

$$
T(X)=T_{\infty}+\left(T_{b}-T_{\infty}\right) * \frac{N r}{D r}
$$

where,

$$
\begin{gathered}
N r=\cosh m(L-x)+\left(\frac{h}{m k}\right)+\sinh m(L-x) \\
D r=\cosh m L+\left(\frac{h}{m k}\right)+\sinh m L
\end{gathered}
$$

\subsection{Heat Transfer Coefficient Using Vertical Plate Correlation}

Correlations given below are used to find the heat transfer coefficient using dimensional analysis for vertical plate [21]. 


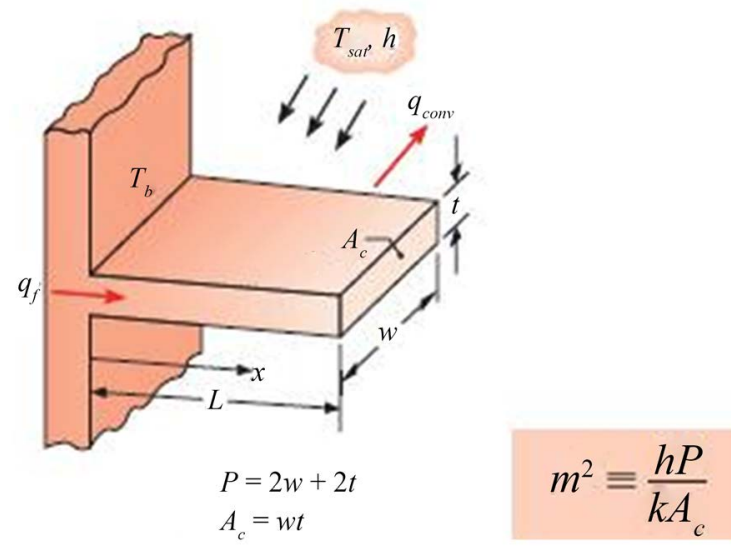

Figure 2. 3D view of rectangular fin.

$$
N u_{L}=\frac{h * L}{k}=C\left(\frac{g \beta L^{3}}{v a} *\left(T_{s}-T_{\infty}\right)\right)^{n}
$$

where,

$$
h=C * \frac{k}{L}\left(\frac{g \beta L^{3}}{v a} *\left(T_{s}-T_{\infty}\right)\right)^{n}=F K \text { constant } *\left(T_{s}-T_{\infty}\right)^{n}
$$

(where $c=0.59, n=0.25$ ).

\subsection{Mathematical and Finite Element Modeling of Rectangular Fin with Number of Embossing's (2, 4, 8 and 10)}

For analysis and comparison purpose, rectangular aluminum fin with 2, 4, 8 and 10 embossing's was considered but for discussion only fin with 10 embossing's is presented in the present paper.

Mathematically, the heat transfer coefficient is calculated using the vertical plate correlation using the following correlation.

$$
h_{p s}=h *\left(1+0.75 * \frac{1130.9}{1696.45}\right)=2.28
$$

\section{Results and Discussions.}

\subsection{Solid Rectangular Fin without Embossing's}

Figure 3 shows FE modeling and analysis for a rectangular fin indicating thermal contour. Temperature along the length of the fin calculated analytically is tabulated in Table 1. Figure 4 shows the superpose of FE analysis and analytical results as indicated in Table 1.

It is observed from Table 1 that the root temperature $200^{\circ} \mathrm{C}$ goes on decreases as fin length increases and reaches $192.4^{\circ} \mathrm{C}$ at the tip. From Figure 3 it is again observed that the FE modeling follows the same pattern that the temperature monotonically decreases from $200^{\circ} \mathrm{C}$ to $192^{\circ} \mathrm{C}$. Hence, it is observed from the present research that keeping the base (root) temperature at $200^{\circ} \mathrm{C}$ with power 
Table 1. Tabulation of analytic values of temperature along the length of the fin.

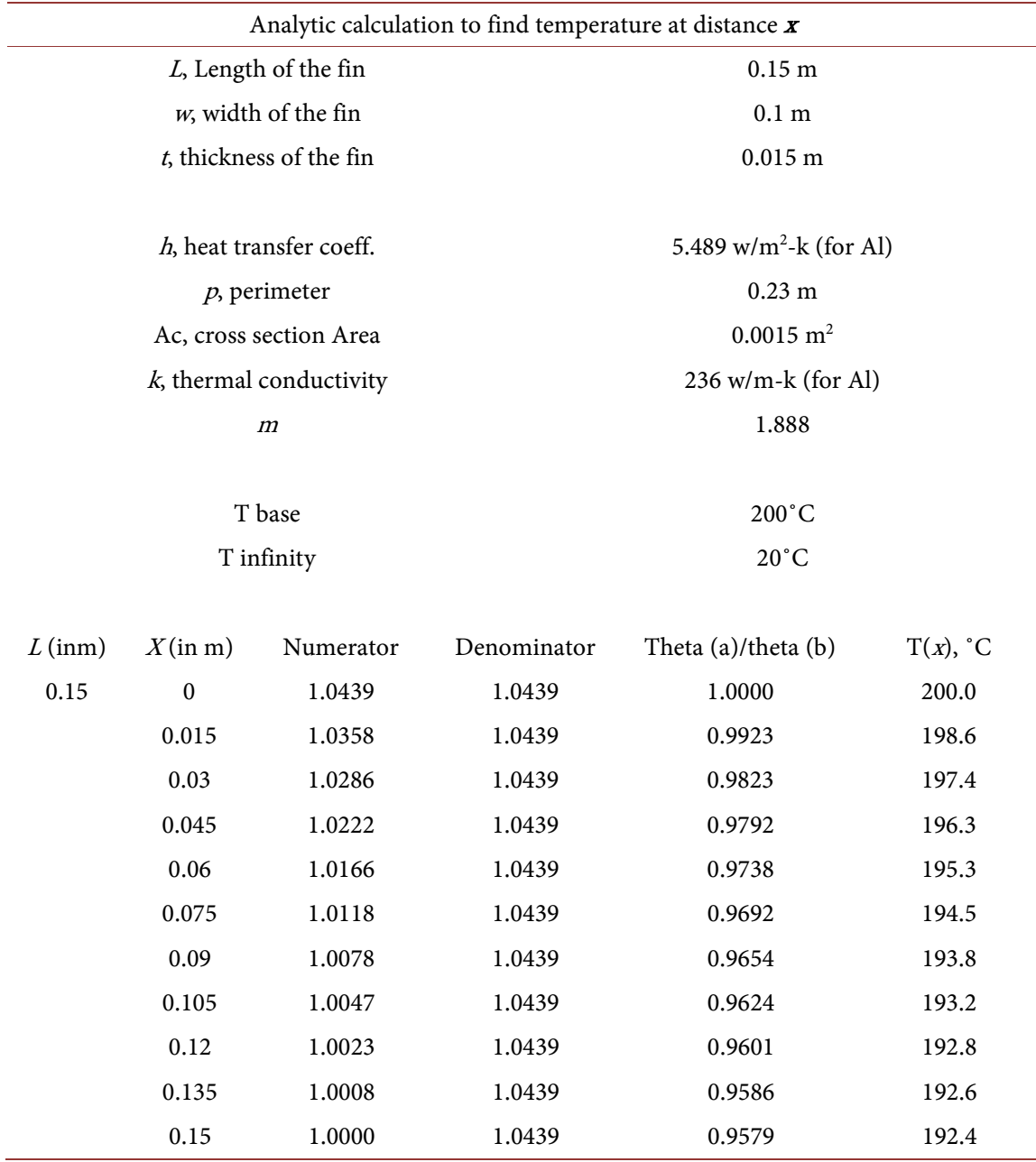

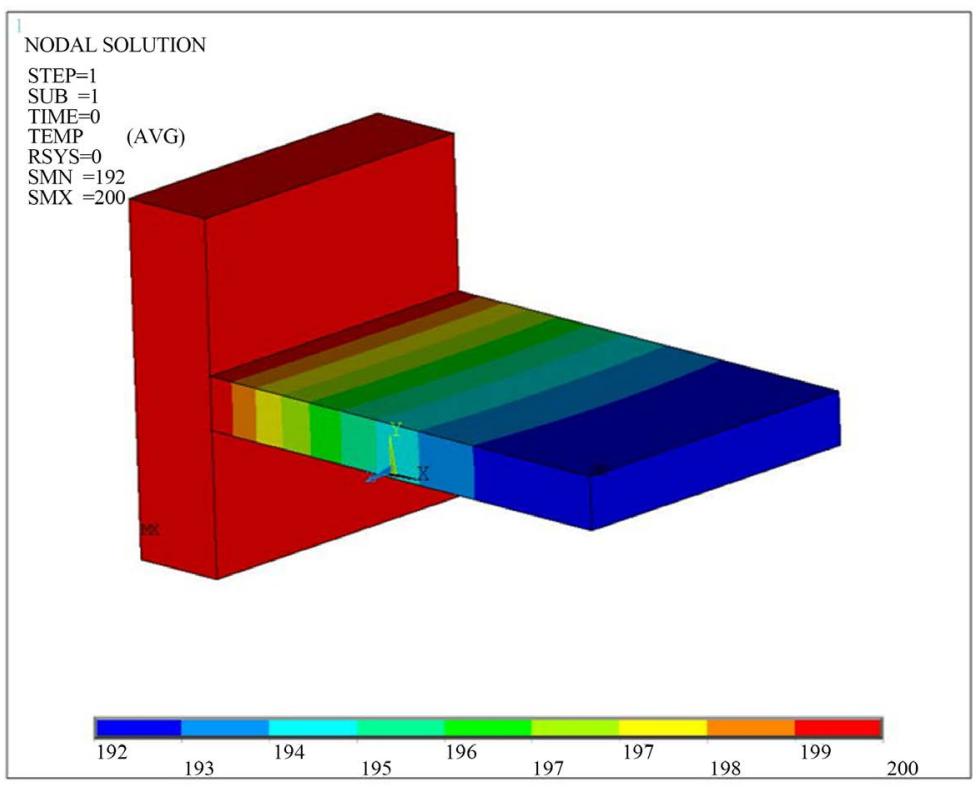

Figure 3. Thermal contour (FE analysis). 


\section{Temparature vs Distance}

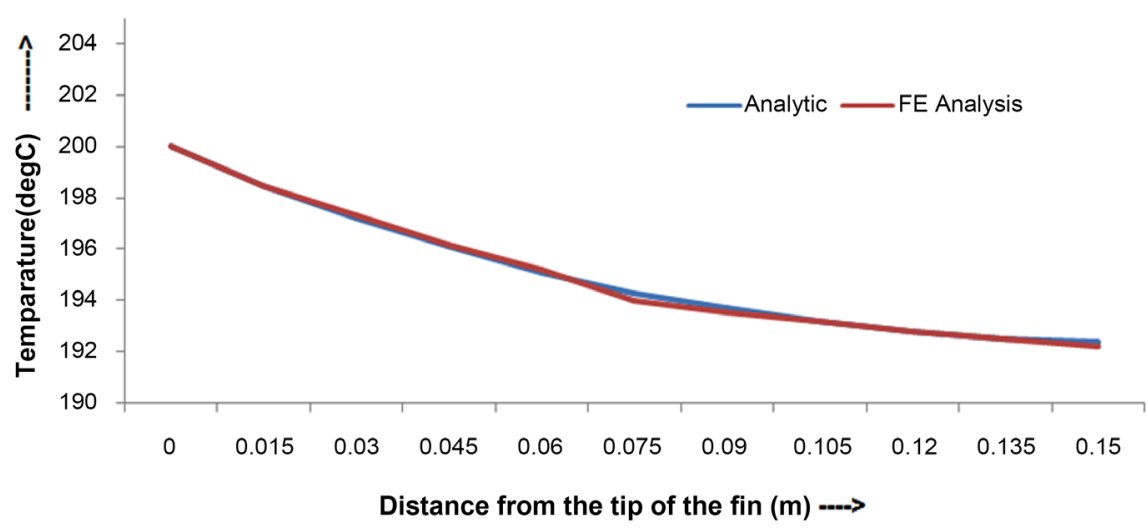

Figure 4. Variation of temperature along the fin length (analytical and FEA superposed).

supply of 40 watts, a solid rectangular fin reaches a temperature of $192.4^{\circ} \mathrm{C}$ at the tip. From Figure 4 it is observed that the mathematical and FEA that for a solid rectangular fin without embossing's are converging within $\pm 1.2^{\circ} \mathrm{C}$ and hence the validity of FEA with mathematical analysis.

\subsection{Solid Rectangular Fin with Embossing's}

Figure 5 shows the experimental results of temperature measurements along the length of the fin with a power supply of 40 watts for a rectangular fin with 2, 4, 8 and 10 embossing's. Temperature was measured using thermocouples along the length of the fin.

Figure 6 shows the temperature calculated using mathematical analysis for a rectangular fin containing 2, 4, 8 and 10 embossing's.

Figures 7-10 show the FE modelling for geometry, meshing, steady state thermal contour and heat flux for a rectangular fin containing 10 embossing's.

It is observed from Figure 5 and Figure 6 that both experimental and mathematical analysis follows almost the same pattern of temperature distribution along the length of the embossed fin. It is also observed from Figure 5 and Figure 6 that the temperature of fin at the trailing surface is decreasing with increase the number of embossing's in the fin. This indicates that heat transfer increases with embossing's having full connectivity between the base and the fin. It is observed from the present research that keeping the base (root) temperature at $200^{\circ} \mathrm{C}$ with power supply of 40 watts, rectangular fin with 10 embossing's reaches $179^{\circ} \mathrm{C}$ at the tip (Figure 9). This shows that rectangular fin with embossing's removes more heat compared to solid fin.

From Figure 9 it is observed that FE analysis follows the same pattern as that of mathematical and experimental values (calculations not shown) i.e., the root temperature $200^{\circ} \mathrm{C}$ continuously decreases to $179^{\circ} \mathrm{C}$ at the tip.

It is finally observed that the mathematical and FEA of rectangular fin with 10 


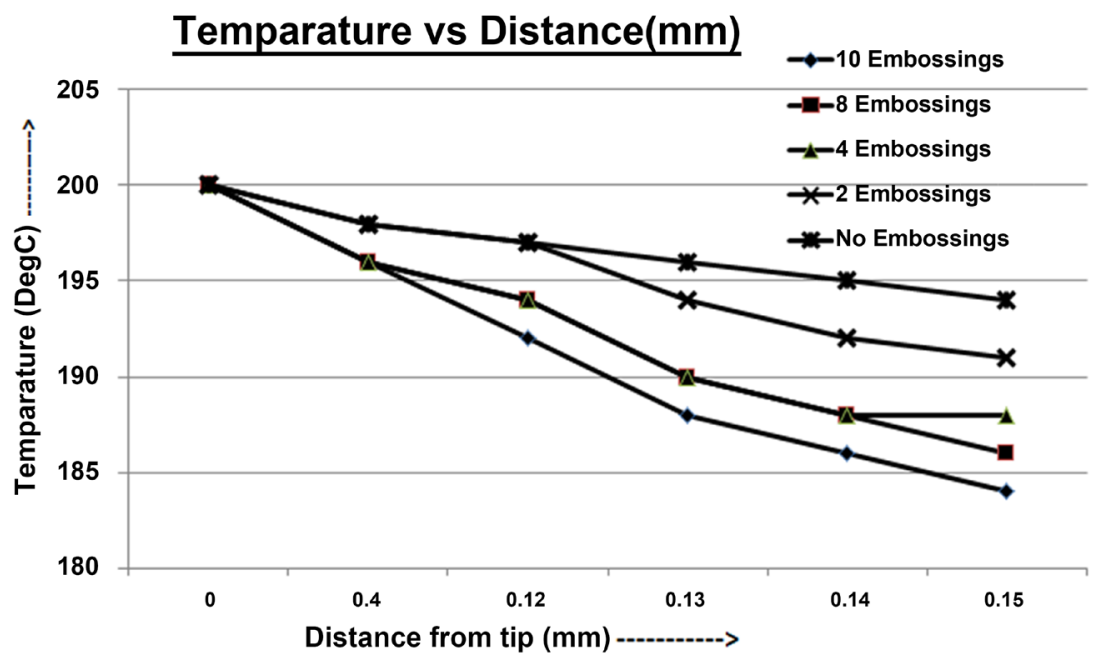

Figure 5. Plot of temperature vs length for a rectangular fin with embossing's.

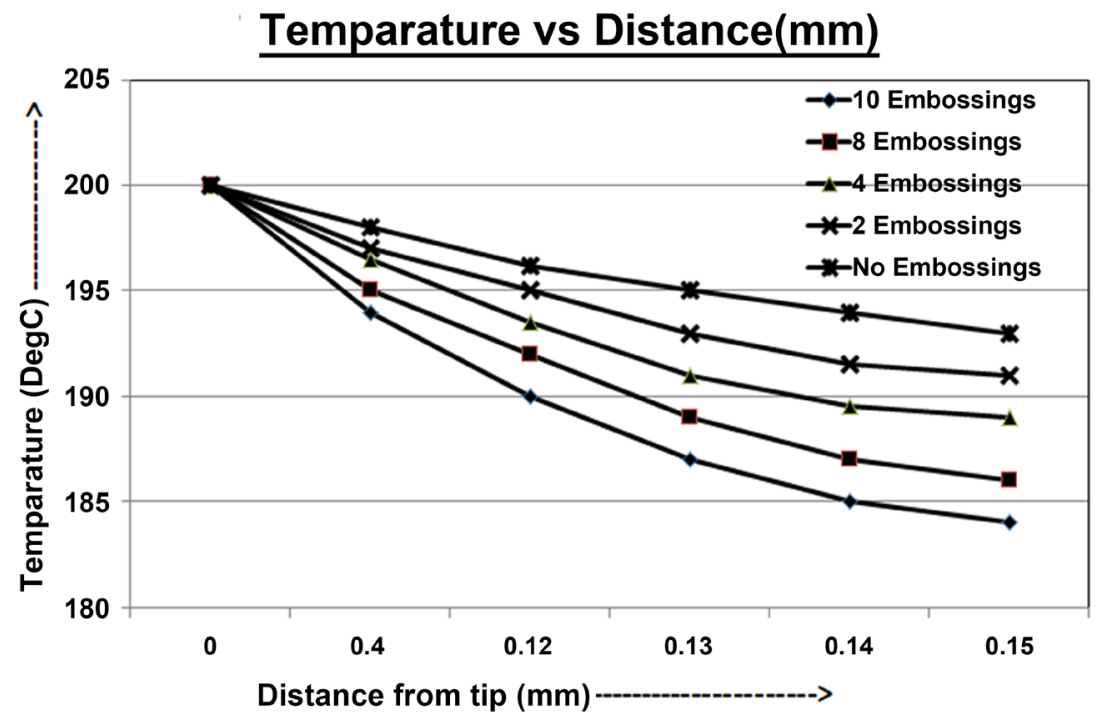

Figure 6. Plot showing temperature vs distance for a rectangular fin with 2, 4, 8 and 10 embossing's by mathematical analysis.
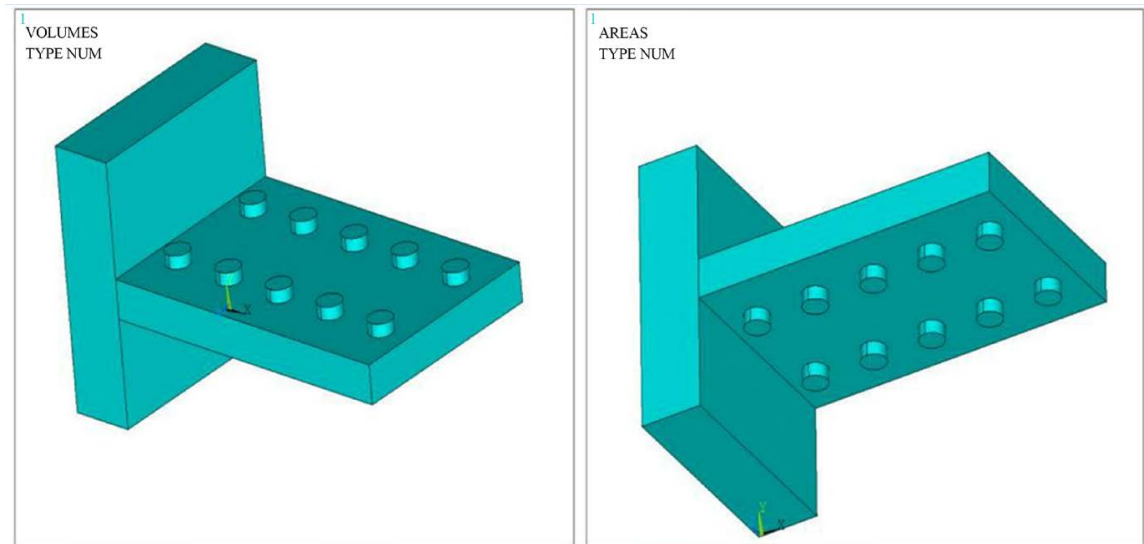

Figure 7. Geometry of fin with 10 embossing's. 

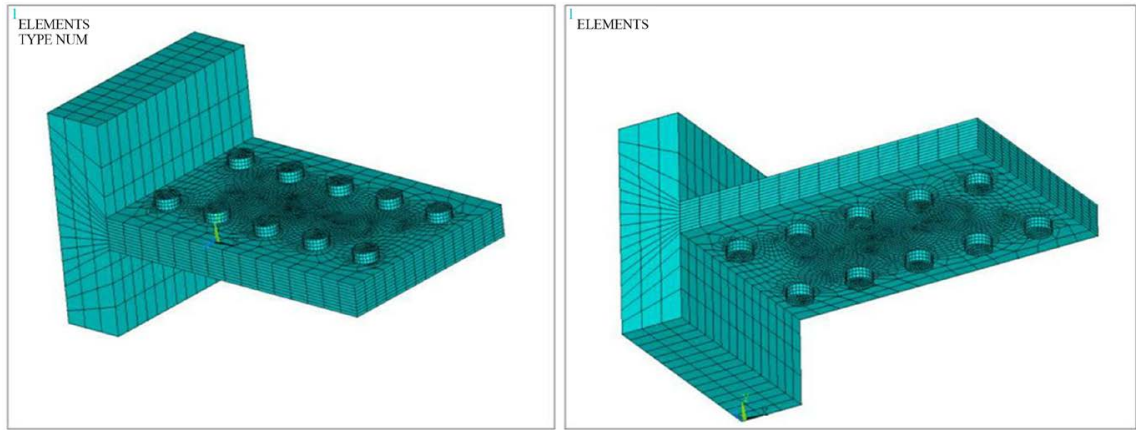

Figure 8. Finite element model (meshing) of the fin with embossing's.

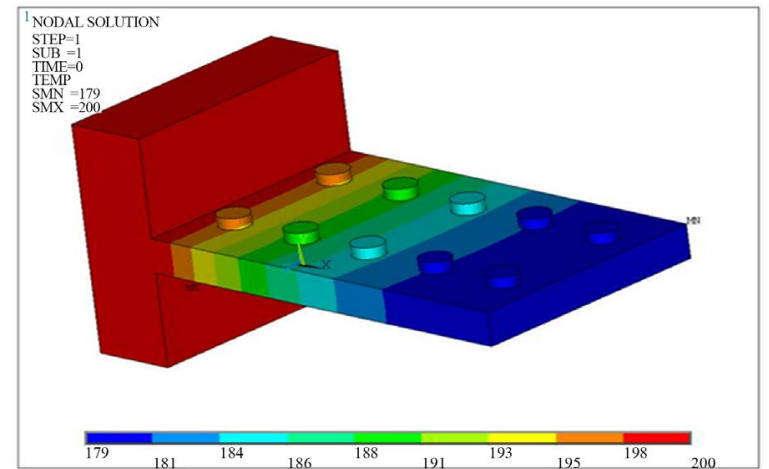

(a)

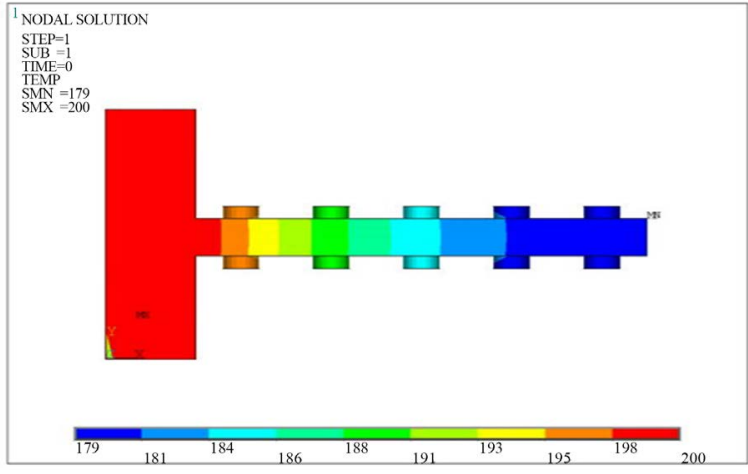

(b)

Figure 9. Steady state thermal contour of embossed fin. (a) Max temperature $=200^{\circ} \mathrm{C}$; (b) Min temperature $=179^{\circ} \mathrm{C}$.
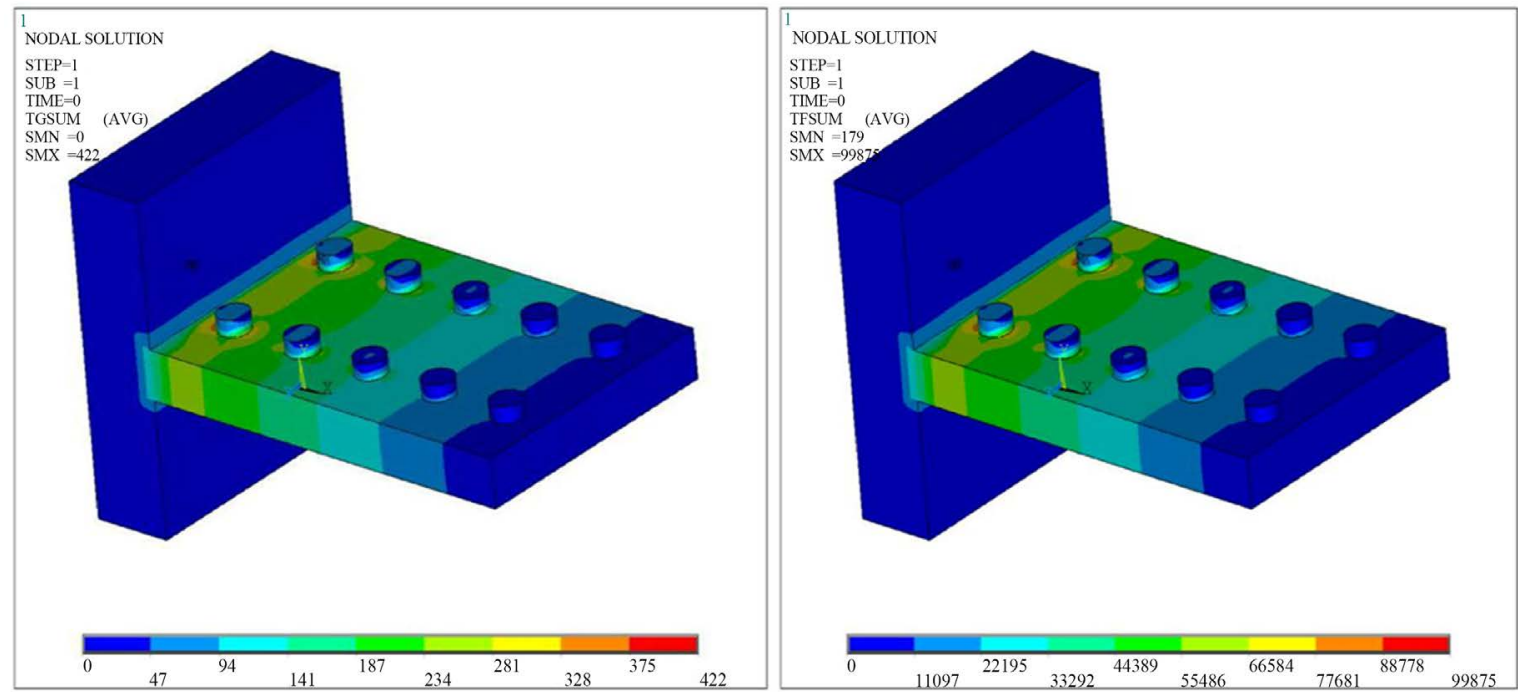

Figure10. Contours of thermal gradient and heat flux of embossed fin.

embossing's are converging within $\pm 1.4^{\circ} \mathrm{C}$ and hence the validity of FEA with mathematical and experimental analysis.

\section{Conclusions}

It is observed from the present research that keeping the base (root) temperature 
at $200^{\circ} \mathrm{C}$ with power supply of 40 watts, a solid rectangular fin reaches a temperature of $192^{\circ} \mathrm{C}$ at the tip whereas the same fin with 10 embossing's reaches $179^{\circ} \mathrm{C}$ at the tip. This shows that rectangular fin with embosing's removes more heat compared to that of a solid fin. It is also observed from the research that this temperature fall is gradual from fin with 2, 4, 8 and 10 embossing's. Thus the heat removal gradually decreases with increase in embossing's. Heat flux also follows the same pattern along the length of the fin as that of the temperature.

In the present research it is also observed from the mathematical and FEA that a solid rectangular fin without embossing's is converging within $\pm 1.2^{\circ} \mathrm{C}$ and rectangular fin with 10 embossing's is converging within $\pm 1.4^{\circ} \mathrm{C}$ and hence the validity.

\section{Acknowledgements}

Author thank the Govt. sponsored R\&D center, HMSIT, Tumkur, INDIA for extending its facilities for carrying out the research and to Mr. J. Joy Gideon, Research Asst. of the R\&D center for assisting in graphics, typing and final setting of this research paper.

\section{References}

[1] Abdullah, H., Al Essa, M.I. and Al-Widyan (2008) Enhancement of Natural Convection Heat Transfer from a Fin by Triangular Embossing's of Bases Parallel and toward Its Tip. Jordan University of Science and Technology, Irbid, 1033-1044.

[2] Baruah, M., Dewan, A. and Mahant, P. (2011) Performance of Elliptical Pin Heat Exchanger with Three Elliptical Embossing's. Department of Mechanical Engineering, Indian Institute of Technology, Guwahati, 25-32.

[3] Elshafei, E.A.M. (2010) Natural Convection Heat Transfer from a Heat Sink with Hollow/Perforated Circular Pin Fin. 2010 3rd International Conference on Thermal Issues in Emerging Technologies Theory and Applications, Cairo, 19-22 December 2010, 13. https://doi.org/10.1109/THETA.2010.5766397

[4] Khoshnevis, A., Faramarzetalati and Maziyarjalaal (2009) Heat Transfer Enhancement of Slot \& Hole Shape Embossing's in Rectangular Ribs of a 3-D Channel. 17 th Annual (International) Conference on Mechanical Engineering, ISME, 19-21 May 2009, Tehran.

[5] Shaeri, M.R and Yaghoubi M, (2009) Numerical Analysis of Turbulent Convection Heat Transfer from an Array of Perforated Fins. International Journal of Heat and Fluid Flow, 30, 218-228. https://doi.org/10.1016/j.ijheatfluidflow.2008.12.011

[6] Karabacak, R. and Yakar, G. (2011) Forced convection Heat Transfer and Pressure Drop for a Horizontal Cylinder with Vertically Attached Imperforate and Perforated Circular Fins. Energy Conversion and Management, 52, 2785-2793. https://doi.org/10.1016/j.enconman.2011.02.017

[7] Dhanwade, K.H., Sunnapwar, V.K. and Dhanawade, H.S. (2006) Theraml Analysis of Square and Circular Perforated Fin Arrays by Forced Convection. International Journal of Current Engineering, 26, 1990-1997.

[8] Ganorkar, A.B and Kriplani, V.M. (2012) Experimental Study of Heat Transfer Rate by Using Lateral Perforated Fins in a Rectangular Channe. MIT International Journal of Mechanical Engineering, 2, 91-96. 
[9] Sahin, B. and Demir, A. (2008) Performance Analysis of a Heat Exchanger Having Perforated Square Fins. Applied Thermal Engineering, 28, 621-632.

[10] Karthikeyan, R and Rathnasamy (2014) Article Title. International Journal of Advanced Engineering Science and Technology, 10, 125-138.

[11] Jeng T.-M. and Sheng, C.Z. (2007) Heat Transfer through Porcelaine Pores Media. International Journal of Heat and Mass Transfer, 50, 2364-2375.

[12] Babus, R.F., Haq, K. Akintunde, S.D. and Probert, (1995) Thermal Performance of a Pin-Fin Assembly. International Journal of Heat and Fluid Flow, 16, 50-55. https://doi.org/10.1016/0142-727X(94)00005-W

[13] Dhumne, A.B. and Farkade, H.S. (2013) Heat Transfer Analysis of Cylindrical Perforated Fins in Staggered Arrangement. International Journal of Innovative Technology and Exploring Engineering, 2, 225-230.

[14] Tanda, G. (2001) Heat Transfer and Pressure Drop in a Rectangular Channel with Diamond-Shaped Elements. International Journal of Heat and Mass Transfer, 44, 3529-3541.

[15] Vanfossen, G.J. and Brigham, B.A. (1984) Length to Diameter Ratio and Row Number Effects in Short Pin Fin Heat Transfer. Journal of Engineering for Gas Turbines and Power, 106, 241-244. https://doi.org/10.1115/1.3239541

[16] Metzger, D.E., Fan, C.S. and Haley, S.W. (1984) Effects of Pin Shape and Array Orientation on Heat Transfer and Pressure Loss in Pin Fin Arrays. Journal of Engineering for Gas Turbines and Power, 106, 252-257. https://doi.org/10.1115/1.3239545

[17] Sara, O.N., Pekdemir, T., Yapici, S. and Yilmaz, M. (2016) Heat-Transfer Enhancement in a Channel Flow with Perforated Rectangular Blocks. International Journal of Heat and Fluid Flow, 22, 509-518. https://doi.org/10.1016/S0142-727X(01)00117-5

[18] Tomar, Y.S. and Sahu M.M. (2013) Review of Performance Analysis of Extended Surfaces (Fins) Under Free and Forced Convection Heat Transfer. International Journal of Innovative Research \& Development, 2, 73-78. http://www.ijird.com

[19] Yang, K.-S. and Chu, W.-H. (2007) A Comparative Study of the Airside Performance of Heat Sinks Having Pin Fin Configurations. International Journal of Heat and Mass Transfer, 50, 4661-4667. https://doi.org/10.1016/j.ijheatmasstransfer.2007.03.006

[20] Hossain, M.S., Ahamed, J.U., Akter, F., Das, D. and Saha, S. (2013) Heat Transfer Analysis of Pin Fin Array. International Conference on Mechanical Engineering and Renewable Energy, Chittagong, 24-27 December 2013, 1-5.

[21] Keren and Donald, O. (2009) Text Book on Process Heat Transfer. 3rd Edition, McGraw Hill, New York. 